\title{
Defining and Assessing the 21st-Century Physician in Training
}

\author{
Rachel B. Levine, MD, MPH ${ }^{1,1}$ and Danelle Cayea, $M D, M S^{2}$ \\ 'Division of General Internal Medicine, Johns Hopkins Bayview Medical Center, Baltimore, MD, USA; ${ }^{2}$ Department of Medicine, Division of Geriatric \\ Medicine and Gerontology, Johns Hopkins University School of Medicine, Baltimore, MD, USA.
}

KEY WORDS: competency-based medical education; assessment. $J$ Gen Intern Med 30(9):1241-2

DOI: $10.1007 / \mathrm{s} 11606-015-3427-y$

(c) Society of General Internal Medicine 2015

$\mathrm{W}$ e are experiencing a paradigm shift in medical education. Education has moved away from using "time" as a determinant of learner readiness to advance to the next stage and ultimately onto independent practice, to the current competency-based paradigm that focuses on a learner's mastery of specific professional activities as a measure of their fitness for unsupervised practice. This approach creates opportunities for more individualized, developmental-based learning, and how we define competency will drive curriculum development and assessment. For example, defining the specific competencies needed to provide high-quality care may identify gaps in existing curricula. Competency-based education lends itself to "assessment for learning" in which learners utilize regular feedback from multiple sources to improve performance in a set of defined skills and behaviors along a developmental continuum. ${ }^{1}$ Structures that support this model include clearly described competencies that link entrustable professional activities (EPAs) (which represent the work that competent physicians perform when synthesizing and contextualizing knowledge and information to care for patients) to learning experiences that occur in authentic clinical environments with opportunities for individualized assessment coupled with meaningful real-time feedback. ${ }^{2}$

To achieve the full benefit of competency-based education, learners and teachers must have a shared frame of reference around the expectations required to demonstrate competency, and faculty must be skilled assessors who are capable of making valid and reliable decisions regarding entrustment. ${ }^{3}$

The tasks for today's educators are to define the competencies that appropriately describe the 21 st-century physician most capable of providing high-quality care in an increasingly complex system, and then to design methods that accurately and reliably assess those competencies in a way that promotes deep and meaningful learning among physician trainees. The articles in this issue by Hauer et al. ${ }^{4}$ and Hemmer et al. ${ }^{5}$ outline

Published online July 15, 2015 steps for achieving these tasks. Hauer and colleagues provide a roadmap that uses a rigorous approach to defining EPAs for medical students. They employed a holistic approach and engaged stakeholders to build a common framework for shared understanding of a competent graduate. Hemmer and colleagues demonstrate that faculty development involving timely and specific descriptions of learner behaviors based on a shared frame of reference improved validity and reliability of medical student assessments. These two processes are necessary components for assessment for learning. Faculty responsible for guiding students through their professional development must have both a shared understanding of the relevant behaviors and the ability to provide specific feedback about a student's trajectory to aid their advancement.

Hauer et al. set out to define EPAs for medical students, starting from a community-based perspective, and then defining the health needs of the communities their graduates will serve and imagining the "ideal physician graduate" to address those needs. From this vision, physician roles and competencies were identified and described. They then proceeded to operationalize the competencies into EPAs, a challenge many before them have struggled to do successfully. ${ }^{6}$ Throughout this iterative process, they enlisted a broad coalition of stakeholders, including current students, who were firmly invested in the work. Building a broad coalition ensures that the identified EPAs have face validity (this was followed by demonstration of content validity using a variety of techniques) and that there is a shared "frame of reference" among stakeholders around the expectations for demonstrating mastery of the identified professional activities. Finally, the process and the investment in building a shared frame of reference creates a culture that recognizes the changing nature of medical education and may be more flexible and nimble in responding to future needs.

By embedding the work of EPA development into a curricular reform process, development and assessment of curricula can proceed hand-in-hand in order to ensure that teaching and assessment methods promote meaningful learning and desired outcomes. Although not explicitly mentioned by Hauer et al., while clearly demonstrated in the article by Hemmer and colleagues, this process should also drive faculty development initiatives. However, having a shared frame of reference is not a guarantee that faculty 
are prepared to lead learners to mastery, as many faculty do not have training in the "emerging" domains identified by Hauer et al., and thus the need for comprehensive faculty development is even more pressing. ${ }^{7}$

While the process at UCSF was closely tied to the unique institutional mission of the medical school, the authors compared institutional competencies and EPAs with national standards from the Association of American Medical Colleges and reviewed their EPAs with residency program directors to ensure alignment with expectations for new residents. Finally, the authors' plan for piloting the individual EPAs should enhance student engagement and, with faculty involvement in the form of rich individualized qualitative feedback on performance for learners, will likely pave the way for true assessment for learning.

Competency-based assessment and assessment for learning require that faculty are able to accurately observe, describe, and "feed back" to learners their strengths and specific next steps in their development. Hemmer et al. demonstrated that faculty attendance at face-to-face evaluation sessions improved adherence to a shared framework (RIME) for evaluating medical students and also improved validity compared to course director ratings. The authors hypothesized that faculty discussion with course and site directors would allow everyone to share the same frame of reference for student performance. These face-to-face meetings also produced a wealth of information about student performance, which was transcribed into a document that each student received at the end of their clerkship. Detailed narratives such as these allow a more transparent and informative evaluation process for students. As we move forward with competency-based assessment, training of faculty in narrative evaluation around a shared frame of reference can help them in providing the information that students need to guide their further development. These comments are often also a source of information about learners' performance in complex areas that cut across individual EPAs and professional behaviors, and that provide valuable insight about their learning trajectory across the curriculum. ${ }^{8}$ Faculty development workshops and feedback can improve the quality of narrative evaluation and are worthwhile investments for medical schools. ${ }^{9}$ Learners report that these narratives are helpful for self-assessment but that they also desire the involvement of trained faculty to help make sense of them. ${ }^{10}$ Faculty must be able to provide real-time feedback and to help students synthesize narrative assessments into individualized plans for mastery learning.

The simultaneous promise and challenge of competencybased education continues to drive innovation and the creation of an evidence base in medical education. The work of Hauer and Hemmer and their colleagues demonstrates a path for moving forward.

Conflict of Interest: The authors declare that they do not have a conflict of interest.

Corresponding Author: Rachel B. Levine, MD, MPH; Division of General Internal Medicine, Johns Hopkins Bayview Medical Center, 5200 Eastern Ave./Mason F. Lord Bldg, Center Tower, Suite 2300, Baltimore, MD 1224, USA (e-mail: rlevine@jhmi.edu).

\section{REFERENCES}

1. Schuwirth LW, Van der Vleuten CP. Programmatic assessment: From assessment of learning to assessment for learning. Med Teach. 2011;33(6):478-85.

2. Holmboe ES. Realizing the Promise of Competency Based Medical Education. Acad Med. 2015;90:411-413.

3. Hirsh DA, Holmboe ES, ten Cate O. Time to Trust: Longitudinal Integrated Clerkships and Entrustable Professional Activities. Acad Med. 2014;89:201-204.

4. Hauer KE, Boscardin C, Fulton TB, Lucey C, Oza S, Teherani A. Using a Curricular Vision to Define Entrustable Professional Activities for Medical Student Assessment. J Gen Intern Med 2015 (SPI \#3264).

5. Hemmer PA, Dadekian GA, Terndrup CT, et al. Regular formal evaluation sessions are effective as frame of reference training for faculty evaluators of clerkship medical students. J Gen Intern Med 2015 (SPI \#3294).

6. Weinberger SE, Pereira AG, Iobst WF, Mechaber AJ, Bronze MS. Alliance for Academic Internal Medicine Education Redesign Task Force II. Competency-based education and training in internal medicine. Ann Intern Med. 2010;153(11):751-6.

7. Kogan JR, Holmboe ES. Preparing residents for practice in new systems of care by preparing their teachers. Acad Med. 2014;89(11):1436-7.

8. Ginsberg S, Gold W, Cavalcanti R, et al. Comeptencies "plus": the nature of written comments on internal medicine residents' evaluation forms. Acad Med. 2011;86:S30-S34.

9. Dudek NL, Marks MB, Bandiera G, et al. Quality in-training evaluation reports - Does feedback drive faculty performance? Acad Med. 2013;88:1129-1134.

10. Sargeant J, Eva KW, Armson H, et al. Features of assessments learners use to make informed self-assessments of clinical performance. Med Educ. 2011;45:636-647. 